Article

\title{
Integrating Agroecology and Participatory Action Research (PAR): Lessons from Central America
}

\author{
V. Ernesto Méndez ${ }^{1, *}$, Martha Caswell ${ }^{1}$, Stephen R. Gliessman ${ }^{2,3}$ and Roseann Cohen ${ }^{2}$ \\ 1 Agroecology and Livelihoods Collaborative (ALC), Department of Plant and Soil Science and \\ Environmental Program, University of Vermont, Burlington, VT 05405, USA; martha.caswell@uvm.edu \\ 2 Community Agroecology Network (CAN), Santa Cruz, CA 95064, USA; gliess@ucsc.edu (S.R.G.); \\ rose@canunite.org (R.C.) \\ 3 Department of Environmental Studies, University of California, Santa Cruz, CA 95064, USA \\ * Correspondence: Ernesto.Mendez@uvm.edu
}

Academic Editors: Manuel González de Molina, Gloria Guzman and Marc A. Rosen

Received: 3 February 2017; Accepted: 24 April 2017; Published: 28 April 2017

\begin{abstract}
The last decade has seen an increasing advancement and interest in the integration of agroecology and participatory action research (PAR). This article aims to: (1) analyze the key characteristics and principles of two case studies that integrated PAR and agroecology in Central America; and (2) learn from the lessons offered by these case studies, as well as others from the literature, on how to better integrate PAR and agroecology. Key principles identified for effective PAR agroecological processes include a shared interest in research by partners, a belief in collective power/action, a commitment to participation, practicing humility and establishing trust and accountability. Important lessons to consider for future work include: (1) research processes that did not start as PAR, can evolve into it; (2) farmer/stakeholder participation in setting the research agenda, from the outset, results in higher engagement and enhanced outcomes; (3) having the right partners for the desired outcomes is key; (4) intentional and explicit reflection is an essential component of PAR processes; and (5) cross-generational collaborations are crucial to long-term benefits. Key challenges that confront PAR processes include the need for time and resources over longer periods; the complexity of multi-actor process facilitation; and institutional barriers within the academy and development organizations, which prevent shifting investment towards integrated PAR agroecological processes.
\end{abstract}

Keywords: community-based research; farmer cooperatives; transdisciplinary research; coffee; El Salvador; Nicaragua; Mexico

\section{Introduction}

The field of agroecology has gained considerable recognition in the last decade and is now viewed broadly as an approach encompassing a diversity of perspectives. These can vary in terms of academic content, research methods, and practical and political applications [1]. Based on the work by Gliessman (2015) [2] and Méndez et al. (2016) [3], we define agroecology as an approach that seeks to integrate ecological science with other academic disciplines (e.g., agronomy, sociology, history, etc.) and knowledge systems (e.g., local, indigenous, etc.) to guide research and actions towards the sustainable transformation of our current agrifood system. This definition embodies a transdisciplinary-oriented agroecology, integrating different knowledge systems in a search for solutions to the challenges posed by current agrifood system issues [4,5]. It also supports the notion that agroecology is an approach that expresses itself as a science, a practice and a social movement [6], and that it is most effective when these three dimensions converge. The agroecological principle of integrating farmer/local and scientific knowledge represents one of the core intersections of science and practice in agroecology. 
It also provides a natural setting for Participatory Action Research (PAR). Variants of the PAR approach have gained increased legitimacy and applications in a growing number of academic fields, including geography [7], ecology [8], education [9], the health sciences [10] and the social sciences [11].

When used in combination with agroecological principles, PAR offers a practical approach for bringing forward the expertise of non-researchers-including smallholder farmers and others who have deep knowledge of place, content and practices-and who become active partners with those trained more formally in research and experimental design. Ideally, the result of this collaborative work is knowledge that has been co-created and that is actionable. In recent years, a growing number of agroecological researchers have embraced PAR to conduct their investigations [12]. One of the greatest strengths of PAR is that it " ... relies on 'complexity thinking'-non-linear, contingent and context-specific approaches rather than reductionist models." [13]. PAR distinguishes itself by pursuing authentic commitment and contributions from research and non-research partners, as well as seeking transformational actions to address issues of concern to the partners in the process [14]. The PAR approach described in this paper includes iterative cycles of research, reflection and action (Figure 1), and is grounded in a belief that this type of research has a role to play, not only in finding solutions to day to day challenges locally, but also to address complex global issues [1].

PAR has been described as an emergent process. It is not something that you always assert when beginning, but instead a progression that can be achieved with the right intentions and dedicated actors [15]. However, the process requires intention and facilitation, and many researchers interested in using a PAR approach are tempted to skip the initial step of 'testing the waters' due to budgetary restrictions and/or limits of time. We find the term 'preflection', used by scholars focusing on experiential learning [16,17], as a useful descriptor of this initial stage. Figure 1 shows the preflection stage as a period of preparation and planning that is critical for building trust, establishing expectations, and refining the research questions. Another adjustment from previous PAR diagrams is the recognition that reflection and sharing should be interspersed throughout, emphasizing that neither the research nor the action cycles are complete without this component. After the process is initiated, reflection and sharing occur to interpret research and design action, and then again to reflect on results and identify new directions.

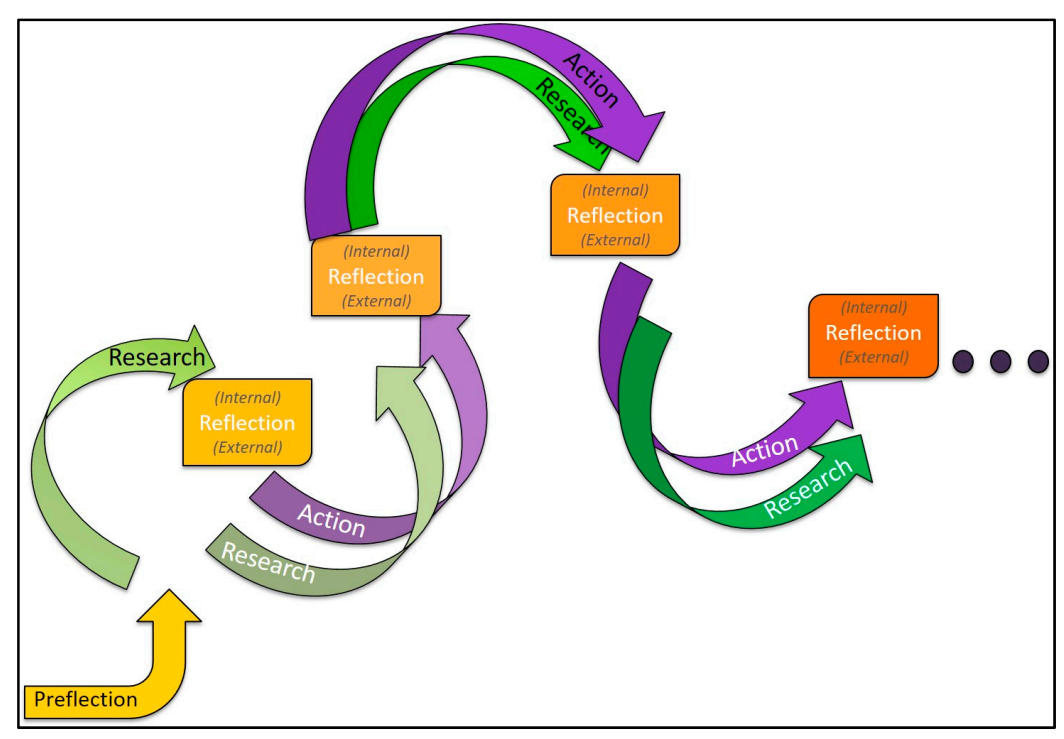

Figure 1. The iterative Participatory Action Research (PAR) cycle (modified and expanded from Bacon et al., 2005 [18]). The image includes a preflection phase-where partners develop a relationship-and several iterations of cycles of research, reflection and action. Darker colors reflect a progressive deepening of the process as it evolves. Reflections can be internal—which only includes the partners involved-but also external, when there is a reaching out to others outside of the PAR initiative to share and/or discuss the process. 
For decades, PAR has been positively associated with agroecology, due in large part to its support for science for the people, and ongoing dialogues of knowledge and emergent properties of systems [19]. However, PAR also struggles with several challenges, including differing levels of participation from specific partners, a process that requires a lot of time and resources, but with a limited reach (i.e., small scale), issues of power imbalances (i.e., who controls the process), and others [18,20,21]. Real trials of scientist/farmer collaborations play out when PAR and agroecology are used in tandem, which inevitably includes challenges of physical access, different observational and/or experimental styles, time constraints and power differentials $[18,20]$. The use of PAR by individuals who have only a passing interest in places or topics has also been criticized, noting that those "... without the time or ability to collaborate with farmers (have) little chance of solving agronomic problems." [20]. Despite these criticisms [20], PAR is also lauded for leading to articulating problems and potential solutions that acknowledge situational perspectives [22], while also demonstrating a utility for helping to understand issues across micro-, meso- and macro-scales [7,23]. A growing number of agroecological researchers have chosen to embrace PAR from the broad universe of participatory research approaches, which span diverse academic disciplines and research methodologies $[7,8,10,11]$. This makes it important to critically assess, learn and share about the limitations of and potential for this integration. The objectives of this article are to: (1) review some of the key characteristics and principles of PAR processes; (2) discuss challenges and opportunities for integrating agroecology and PAR, using two cases that exemplify multiple PAR cycles; (3) extract and discuss lessons from these case studies; and (4) propose recommendations for better integrating PAR and agroecology in future initiatives.

\section{Characteristics and Principles of PAR}

\subsection{PAR Characteristics and Principles}

Given the diversity of interpretations of PAR, we first want to explain how we perceive this complex process, and its phases of research, reflection and action. To begin, we believe that a PAR process can evolve in almost any circumstance where researchers and non-researchers decide to engage in an investigation, which has the aim to better understand or resolve an issue of interest to all the parties involved. In addition, there are different 'points of entry'. Ideally, a potential PAR process would begin with a stage of preflection, as we proposed in the introduction. However, PAR processes are frequently 'impure' and messy, and can begin at any of the stages of the cycle (i.e., preflection, research, reflection or action). Sometimes these processes will evolve into PAR, and other times they will fall short. Hence, determining if a process is meeting the basic requirements of PAR is not straightforward. What seems to determine how the PAR process evolves and the nature of its outcomes is largely a result of the characteristics and principles that participants use and apply in their specific situation [12]. In our work as researchers and scholars we have sought to engage in PAR as much as possible, and we have experienced both PAR processes that were deep, rewarding and that met expected PAR principles, and others that did not. From these experiences, we have identified the following key characteristics that seem to distinguish successful PAR processes:

1. PAR is a complex, negotiated process, where each partner articulates potential contributions, advocates for specific interests and names tangible benefits that they hope to obtain from the process. Through these ongoing negotiations, actors must actively work to identify and name implicit benefits, in addition to confronting traditional power imbalances related to race, gender and class, among others.

2. PAR processes rarely follow a predictable timeline, and often result in periods where focus is more heavily directed toward one of the components of a cycle (i.e., research, reflection or action). Some stakeholders may see the fruits of their labor earlier than others, but the goal is to communicate openly and collaborate for long enough that each party realizes their desired benefit(s). 
3. Patience, flexibility and accountability are key to identifying and assessing emergent features. Each contribute toward PAR processes surviving the changing interests and/or agenda(s) of the partners involved.

4. Long-term collaborations cannot be sustained without significant investments of time and effort (requiring sufficient resources). This often points toward institutional and/or organizational connections that facilitate the succession of active participants without losing forward momentum.

Successful PAR processes tend to be guided by the following key principles:

1. Shared interest in research-PAR facilitates the identification of appropriate solutions (or at least reasonable responses) to real-life problems, through diverse methodologies and with triangulation from multiple perspectives. Partners who are not convinced that research can contribute to their interests will rarely last long in a PAR process.

2. Belief in collective power-Partners believe that engaging in the PAR process is a way to achieve ends that go beyond what is realized through other approaches and there is an intrinsic valuation of each partners' potential contribution.

3. Commitment to participation-Beyond just showing up, all partners share ownership of or have contributing roles in as many phases of the research as possible-starting with defining research questions, through data collection, analysis of results, and eventually engaging in actions that represent co-created solutions.

4. Humility—Space to honor the depth and acknowledge the limitations of each partners' knowledge is fundamental to transdisciplinary work where contextual, practical and technical expertise are each valued.

5. Trust and accountability-Partners recognize that actions, not words, are what establish a strong base for ongoing collaboration, and intentional design includes opportunities for partners to share leadership and mechanisms for resolving conflict.

6. Communication-Partners amplify traditionally marginalized voices and perspectives, acknowledge biases, establish an expectation for transparency and prioritize disseminating results in multiple formats to increase accessibility.

\subsection{Challenges and Conflict in PAR Processes}

PAR processes represent spaces where individuals and organizations with different backgrounds and histories interact (i.e., farmers and researchers, NGOs and universities), or 'engage', which at some point or another will usually lead to some degree of conflict [24]. In addition, PAR work can be transformational, in both positive and challenging ways, at the individual level, which can lead to both personal and inter-personal conflicts [25]. Several authors have outlined frequently encountered issues that PAR practitioners should be vigilant about, and which can help to both preempt different types of conflicts, as well as find ways to resolve them. These include an awareness and examination of the presence of 'invisible actors', tensions between academics and non-academics in agenda setting, and doing no harm when faced with the 'dirty laundry' brought by some of the partners [26]. PAR is also a process fraught with power dynamics, which relates not only to the gender, class and race of the partners, but also to the internal dynamics of both researcher and non-researcher communities [7,14,25]. As in any social process, dealing effectively with existing or emerging conflicts is essential for PAR to succeed. In this regard, it is hard to propose universal strategies, as each context will bring a specific set of conflicts that will need to be addressed in a unique way. However, we believe that some of the principles we have outlined in the previous section, and the articles discussed in this paragraph, provide some guidance on how to engage with some of these pervasive challenges.

\section{Integrating Agroecology and PAR}

An upsurge of projects that attempt to integrate PAR and agroecology has made it more important to critically analyze this approach. Méndez and colleagues [1] discussed the alignment of PAR and 
agroecological principles, including valuing different types of knowledge systems, paying attention to local context, and acting at multiple spatial and socio-political scales. There are many experiences integrating PAR with agroecology in a variety of contexts, which have been documented in the academic literature. For example, Dlott and colleagues incorporated this approach into their work on pest management with peach farmers in California [22]. In Southern Spain, researchers associated with the agroecology graduate program at the International University of Andalucía (UNIA), the University of Córdoba (UCO), and the Pablo de Olavide University (UPO), have carried out long-term PAR and agroecology-oriented processes with a variety of farmers $[19,27]$, focusing on issues of ecological production, certification and markets. The Community Agroecology Network (CAN) has collaborated on PAR processes with Santa Clara University and the University of Chapingo, oriented towards food security and sovereignty with coffee farmers in northern Nicaragua $[28,29]$ and Mexico [30], respectively. In Malawi, a collaborative including African, U.S. and Canadian universities and non-government organizations has used the PAR approach to assess agroecological management as a contribution to rural households affected by HIV/AIDs [31,32].

The following sections elucidate how some of the PAR characteristics and principles, as well as the challenges of integrating agroecology and PAR, played out in two long-term case studies in Central America and Mexico.

\section{Case Study 1: Agroecology and PAR with Smallholder Coffee Farmers in El Salvador}

\subsection{Overview}

The PAR process outlined in this section took place between 1999 and 2013, and although it is in hiatus right now, it might be resuscitated in the future. The process started as the doctoral dissertation of the first author of this article, subsequently referred to as the 'lead researcher' [33]. It had an explicit agroecology focus and evolved into a PAR process over time. This follows the trajectory of those who describe PAR as an emergent process, which means it is not something that you can assert at the beginning, but instead a progression that can be achieved with the right intentions and dedicated actors [15]. The results of this work have been reported in numerous publications, including manuscripts more ecologically focused [34], others more interdisciplinary [35,36], and yet others that explicitly addressed the PAR component $[18,35]$. The process took place in the municipality of Tacuba, located within the western coffee growing region of El Salvador. The PAR process mainly involved three smallholder coffee farmer cooperatives, although other farmers also participated, as well as a diverse group of research and non-research actors (see [30,31] for detailed descriptions of the site).

The general objective of the original research was to assess whether small-scale coffee farmers and cooperatives of El Salvador could develop/maintain strategies that supported both biodiversity conservation (more specifically, native trees) and household livelihood strategies. The lead researcher, without the participation of the farmers, set this objective. In other words, the preflection phase was not explicit, but took place during phase 1 of the research, as the different partners were developing relationships and building trust (Figure 2). What is important to note is that the initial research objectives were developed with limited participation from farmers. However, as the lead researcher was committed to PAR principles, this initiative evolved into a PAR process over time. To better understand the process, we have divided it into three phases (Figure 2), but it is important to consider that this division represents the perspective of the lead researcher. If other partners (e.g., farmers) were to describe it, they might do it differently, and their interpretation would be just as valid. These phases are described in more detail in subsequent sections. 

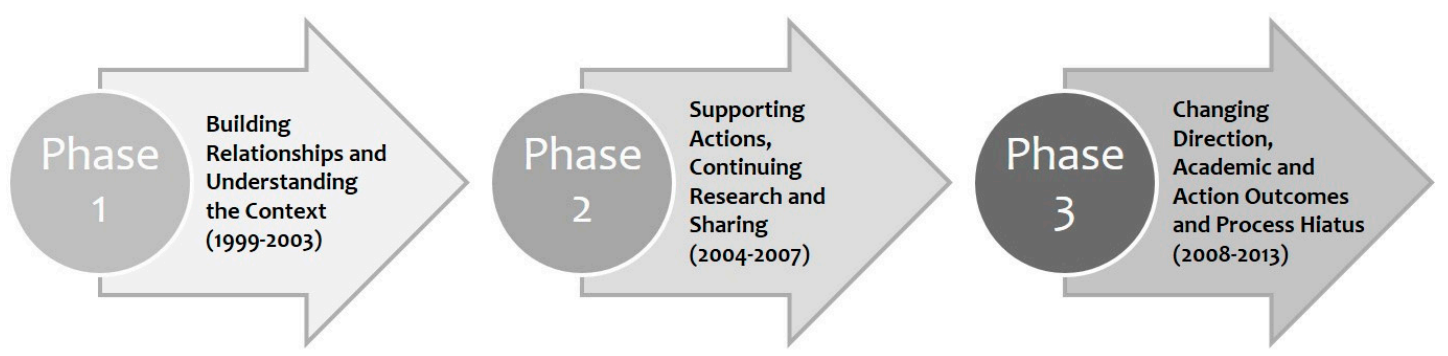

Figure 2. The three phases of the Participatory Action Research (PAR) process with smallholder coffee farmers in Tacuba, El Salvador.

\subsection{Application/Integration of PAR and Agroecological Principles}

(1) Shared interest in research-The lead researcher pursued his research agenda on agroecology, biodiversity and livelihoods, without much input from farmer partners at the beginning of the process. Given that farmers were not a part of setting the initial research objectives, they were not as engaged in the project and more interested in negotiating different types of support that the lead researcher could provide, such as networking, capacity building and helping them get their farms certified as organic or fair trade. As the process evolved, farmers were able to re-direct the research towards food security, which had become an issue of higher relevance at the time. In turn, the research team was able to contribute its agroecological perspective to developing farming alternatives, whereas other projects in the region focused on more conventional approaches (e.g., using synthetic inputs for production). When farmers were able to choose the research theme, they became more involved in the research process.

(2) Belief in collective power-Although the lead researcher had a belief in collective power, farmers were initially skeptical. This shifted when farmers were able to attain tangible benefits from the process, such as organic certification and learning about the factors affecting food security levels in the different households. It is important to recognize that the cooperative sector in El Salvador has had a tumultuous history, affected by issues of corruption and mistrust, which also hindered farmer confidence in collective processes. Many of the cooperative members are very distrustful of external actors and this made it harder to establish a sense of collective power.

(3) Commitment to participation-In this instance full participation increased as the process evolved, and once established, both farmers and researchers became more fully committed. That said, a culture of paternalism infused the process throughout. Farmers had had very few experiences of having full participation in initiatives with external actors, so their commitment to being active participants was sometimes ambiguous and inconsistent. For example, at times they would be very eager to participate in a variety of activities and at other times they wanted the research team to do most of the work. Participation and the level of available resources was a regularly negotiated issue throughout the PAR process.

(4) Humility-Humility was a key principle for this process throughout. During Phase 1, the lead researcher was very transparent and humble in terms of accepting a lack of knowledge of the context and realities that farmers faced, and a willingness to learn from farmers. This opened the door for deepening a relationship of trust. During later stages, as decision-making led to discussion and debates, humility was a principle to be intentionally remembered and practiced. It was easier to maintain this between researchers and farmers, than between farmers from different cooperatives. Although humility may not be an explicit principle of agroecological practice, it is implicit when valuing the different types of knowledge held by different actors. Farmers will seldom share their knowledge with outsiders who act and/or believe they bring a superior understanding or perspective. 
(5) Trust and accountability - Trust and accountability was a principle brought to the process from the onset. It started with the lead researcher communicating a commitment to pursue a relationship with farmers through a process that was grounded in trust, and where people held themselves accountable. This intentionality and commitment to trust and accountability was well-received by farmers but they were clear that it was something that had to be proven by concrete actions and over time. All actors constantly revisited this throughout the process. One area that could have been improved was to define clear accountability mechanisms. In this case, it was loosely assessed by taking inventory of tangible actions or outcomes, rather than an explicit monitoring of the process that examined if partners were doing what they were committing to do.

(6) Communication-A commitment to clear and constant communication was a strength of this project. This meant that energy and resources were invested in assisting farmers who lived far away to be able to come to meetings (i.e., providing transportation and meals), and providing access to a phone in the office maintained by researchers in the town of Tacuba. An important first step was for the lead researcher to spend a considerable amount of time (the first two years) living in the town. This allowed for constant and consistent conversations that led to finding the best modes of communication among different partners.

\section{Timeline}

\subsection{Phase 1 (1999-2003)}

The first phase of the process involved exploratory research to establish participating partners and objectives, as well as a subsequent phase of in-depth research on livelihoods and biophysical characteristics of the shade coffee plantations. The lead researcher reached out to the leaders of the three cooperatives to act as collaborators in the research process. The site had been selected for its ecological importance as a buffer zone to a national park, and because of the presence of numerous smallholder coffee farmers and cooperatives. The lead researcher had training and interest in PAR, and from the beginning opened up a dialogue to discuss ways in which the research could benefit farmers. In addition, there was an emphasis on transparency, explaining the lead researcher's background (e.g., middle class, urban Salvadoran), and how the process would benefit him (i.e., completing his dissertation and contributing toward his future career). This provided the farmers with a foundation from which to negotiate for their own interests. Although these initial steps align well with PAR, what did not follow a PAR approach was that the lead researcher developed the initial research without the participation of the farmers (partly, as a result of the $\mathrm{PhD}$ and dissertation structure/process). In turn, farmers outlined areas of support where the lead researcher could help. These were indirectly linked to the research questions, in the sense that they affected farmer livelihoods, but not necessarily through biodiversity conservation management. The areas of interest that the farmers identified were: (1) support to become organic and Fair Trade certified, including capacity building; and (2) support to expand their networks with national and international development organizations, which could potentially bring agricultural and rural development projects to their communities. This period of the process took the place of preflection, and mostly focused on relationship building. From a research perspective, extensive data collection was undertaken, but because analyses were just starting, there were few finished products in the form of publications and presentations.

This stage also included action-oriented activities facilitated by researchers, in the form of capacity building on biodiversity conservation and ecosystems services, organic and Fair trade certifications, and building cooperative unions. A key accomplishment at the end of this period was a farmer-to-farmer exchange with cooperatives in Nicaragua. Fifteen Salvadoran farmers and several researchers visited cooperatives in the northern coffee zone of Nicaragua. The objective was to learn about certifications, coffee quality control and cooperative models. In general, the highlights of this phase of the process were action outcomes related to capacity building and advancing towards organic certification of the cooperatives. 


\subsection{Phase 2: Supporting Actions, Continuing Research and Sharing with Others (2004-2007)}

This phase was characterized by shifts in the situations of researchers, a deepening of academic outcomes and advances in strengthening farmer organizations. First, after the trip to Nicaragua in 2003, farmers were motivated and enthusiastic in pursuing a union among the three cooperatives, based on the model they had observed in northern Nicaragua. The research team supported this initiative and the legal process advanced substantially. Although morale was high in terms of the potential benefits of forming a union, tensions among the leaders of the three cooperatives were present from the onset. In addition, all three cooperatives attained organic certification and support from several external projects in organic management. This was perceived by farmers as a very positive outcome stemming from the process.

From a research perspective, several graduate theses were undertaken with the support of the research team and vetted by the farmer cooperatives, which resulted in published manuscripts (one peer-reviewed article in English, several extension publications and research reports in both English and Spanish). This helped to provide visibility and credibility to the process, which assisted the farmers in their negotiations with NGOs and donors, and helped them to participate in several projects. Several members of the research team also got involved with other research and development initiatives that provided opportunities for internal and external sharing. However, by the end of this phase, two lead researchers in the process had moved outside of El Salvador for professional and personal reasons. This shift had an effect on the functioning of the process as these two people had been working with farmers for almost a decade. Notwithstanding, the office in Tacuba remained open, and the more stable position obtained by the lead researcher at the University of Vermont (UVM) in the U.S. allowed for an increase in resources. These included covering the costs of maintaining the office and staff, funding graduate student projects and launching an undergraduate study abroad course, which provided revenue for the cooperatives.

\subsection{Phase 3: Changing Direction, Academic and Action Outcomes and Process Hiatus (2008-2013)}

This stage saw a true transformation of the research into a PAR process. As the spike in global food grain prices confronted farmers in 2008, they became interested in further exploring the issue of food security. The research team responded by re-directing research and reaching out to learn and interact with other efforts focusing on food security in several coffee regions of Mesoamerica. Two doctoral students from UVM focused their dissertations on this topic [37,38], and new collaborations with work in Nicaragua and Mexico emerged. Research outcomes from these efforts included a significant number and wide variety of publications in English and Spanish, including an edited book on agroecology, livelihoods and the coffee price crisis [39]. The research stemming from this period had a more direct application to the issue of food security, as investigations covered causes and possible alternatives for farmers to better deal with this issue. In addition, agroecology was at the core of the food production research, including topics such as the performance of local corn and bean landraces [38], the costs of synthetic inputs [40], and the possibility of transitioning from conventional corn and bean production to more agroecological alternatives.

This phase was also rich in action outcomes, albeit not without conflict. The farmers were able to legalize their union of cooperatives-the Association of Organic Coffee Producers of Western El Salvador (ACOES) - but in the process the largest of the organizations decided to pull out, leaving the union with a relatively small number of farmers and coffee volume. This was a hard blow to an initiative that had taken years to build. On a more positive note, ACOES was able to establish a direct relationship with a progressive coffee roaster in the U.S. and Canada. Coffee was sold at very favorable prices for two years. Again, this was a team effort between farmers and researchers that took a lot time and energy, as there was no experience of the export process, which was very complicated.

The steps that led to a hiatus in the process started in 2011. Funding for the research team was decreasing, which resulted in the closing of the office in Tacuba. In addition, ACOES decided to stop selling their coffee to the roaster that had been recruited earlier; a decision that was hard on the 
researchers, given that they had invested considerable time and effort to develop this relationship. It is important to note that the distance that existed between the farmers and the lead researcher was taking its toll on relationships, which affected the levels of trust and transparency in the process. In 2012, a former UVM student who had done his undergraduate thesis in Tacuba and had begun working with a progressive coffee roaster in the eastern U.S., sought out the lead researcher to explore the possibility of buying coffee from ACOES. For the next two years, and with a perception of interest and enthusiasm from ACOES, the roaster and the lead researcher visited Tacuba and explored the development of this relationship. Unfortunately, after much effort from all parties the farmers decided not to move forward. These final actions led to a hiatus in the process, with the lead researcher feeling a breach of trust in the relationship, as well as lacking the necessary resources to continue the process.

\subsection{Lessons Learned}

- This case study shows that, over the long-term, a research process that did not necessarily start as PAR can be transformed into one if there is intention and commitment from the partners.

- A key part of this process was the establishment of open and transparent negotiations. This allowed for both researchers and farmers to pursue goals and benefits of interest. Sometimes these goals were not the same, but the benefits obtained by each partner exceeded the costs of time and resources to continue to support the process as a whole.

- When farmers were able to participate in deciding the research themes and contribute to research planning, they were much more engaged in the research and the potential resulting actions.

- It is important to have the right partners that align well with desired outcomes. Although the outcomes of the work, over 14 years, were considerable in terms of academic output and tangible benefits for farmers (actions), this process was missing a key partner that could more consistently support farmers in implementing the actions and initiatives emerging from the process. This additional actor would have ideally been an organization 'on the ground' (i.e., a local NGO or a government extension unit), which could provide accompaniment as farmers implemented new practices and worked as a new association. Researchers were limited in terms of time and resources to be able to maintain a presence with the level of stability and focus on implementation that seemed to be required.

- Reflection is very important and needs explicit intention and attention. In this process, reflection was implicit and somewhat $a d$ hoc in practice. Making it more explicit and intentional may have served to better evaluate and direct the process.

- Although this was a long-term process with a considerable investment of time from the research team, there is uncertainty that it was as expensive as might be perceived. This points to a need to better analyze the costs of PAR processes, as many question the validity of PAR due to being too slow and too expensive.

\section{Case Study 2: The Community Agroecology Network's (CAN) Agroecology and Participatory Knowledge Production and Exchange in Mexico and Nicaragua}

\subsection{Overview}

The Community Agroecology Network (CAN) is an international non-profit organization committed to sustaining rural livelihoods and environments through collaborative research, education, capacity building, and locally informed development strategies [41]. Agroecology is at the heart of CAN's work to produce knowledge and develop socially just and ecologically sound practices that create a more sustainable food system. CAN operates as a network, partnering with community-based organizations, farmers' cooperatives, nonprofits and universities. Together, CAN and its network partners pursue a vision of communities that experience food sovereignty, resilience to climate change, sustainable rural livelihoods, and participation across gender, generations, ethnicity and social class (see http://www.canunite.org). 
CAN engages in participatory action research (PAR) to facilitate collaborations between farmers/farmworkers, community-based organizations and scientists to collectively identify problems and action agendas through a reflection process. This requires long-term intercultural relationships with local partner organizations based on mutual humility, trust, accountability and learning. Thinking with- and not for-communities allows room for experimentation and leads to context-specific strategies that are more likely to be sustainable and scalable. Successful actions from each PAR process are shared throughout CAN's network through peer-to-peer and farmer-to-scientist learning exchanges.

The case study discussed in this section focuses on a five-year PAR initiative (2011-2015) with coffee-growing communities in San Ramon, Nicaragua. The Youth Leadership and Education for Sustainable Agriculture and Food Sovereignty Project (referred to as YLFS Project) was a collaboration between CAN, the Union of Cooperatives of San Ramon (UCA San Ramon) in Nicaragua, and the NGO Vinculación y Desarrollo Agroecológico en el Café/Agroecological Networks and Development in Coffee (VIDA) in Mexico. The project aimed to alleviate food insecurity and seasonal hunger by strengthening livelihoods among 234 coffee farming families and building sustainable local food systems across 12 coffee-growing communities. The project design positioned youth and women as leaders of the initiative through capacity building and empowerment. Further strengthening the objectives of the YLFS Project, coffee farmers in San Ramon and Veracruz joined CAN's alternative coffee trade model, AgroEco ${ }^{\circledR}$ Coffee. AgroEco ${ }^{\circledR}$ Coffee is a much-shortened coffee value chain that promises higher returns to farmers focused on solidarity, participation and transparency. All supply chain actors (farmers, cooperatives, importer and roaster) sit at the negotiating table to set prices each year. CAN facilitates relationships, provides capacity building and monitors the impacts of AgroEco ${ }^{\circledR}$ Coffee. It is not a certification, but rather a long-term commitment by all actors to support each other in the transition to an agroecological production and trade model. This transition is supported by the "Sustainable Agriculture Fund" and the "Women's Unpaid Labor Fund," included in the price paid by the coffee roaster, and invested based on the collective decision-making of farmers and women, respectively.

In the case study discussed, we highlight two examples: the integration of vegetable-focused homegardens into crop production systems to improve household dietary diversity and diversify women's income, and the development of AgroEco ${ }^{\circledR}$ Coffee's Women's Unpaid Labor Fund, which recognizes women's reproductive and productive labor in coffee production. Both examples demonstrate the challenges, lessons learned and positive outcomes when integrating PAR and agroecological principles.

\subsection{Application/Integration of PAR and Agroecological Principles}

(1) Shared interest in research-CAN pursues partnerships with researchers and local organizations to conduct collaborative research focused on the development of evidence-based actionable results. Partners share an interest in addressing injustices in the food system and working toward food sovereignty. PAR begins by opening a dialogue and organizing intentional spaces for focused discussion with various stakeholders, in order to determine research agendas and methods, so that results will be relevant and scalable.

(2) Belief in collective power - CAN functions as a network and a learning organization. It brings together researchers, local organizations and the communities they serve to share lessons learned from the ground-up. It recognizes and values different ways of knowing, and promotes intercultural exchange of knowledge and practices as a key tool to achieving food system transformation.

(3) Commitment to participation-Smallholder farming families and farmworkers are engaged with CAN and local organizations in collaborative research processes that build capacity and identify solutions connected to their particular context and aspirations. In order to achieve broad participation, PAR should integrate methods for addressing power relations and diversity within and across stakeholder groups. The goal is to democratize knowledge production by making 
science work for the people. It focuses on capacity-building with community partners, so that community mobilizers (i.e., youth promoters in the case study discussed) learn to conduct research in their own communities, and support their communities in making evidence-based decisions for food systems change.

(4) Humility-Humility refers to a process of self-reflection that addresses inequality. It requires that we commit to life-long learning, recognize knowledge and perspectives other than our own, and build mutually respectful and dynamic partnerships with others to work toward systemic change [42]. Agroecology is a concept with roots in indigenous knowledge systems-ways of knowing and interacting with local ecologies that emerged from peoples with deep connections to soil, land, plants, animals, and growing food (see www.canunite.org). Scientists that developed the academic field of agroecology learned from observing farmers, trying things out together and communicating across knowledge systems [2]. Those most affected by the injustices of the food system-people of color, indigenous communities, women, farmers and food workers-are now shaping agroecology into a people's science movement and practice [43,44]. PAR offers an approach to learn from alternative agrarian histories and the challenges marginalized producers and consumers face in their daily lives. It is crucial that we listen and learn from these struggles. Otherwise, we risk furthering the power imbalances that create deep inequities in our food system, and losing knowledge with the potential to transform food systems from the ground up.

(5) Trust and accountability -Partners recognize that actions, not words, are what establish a strong base for ongoing collaboration; intentional design includes opportunities for partners to share leadership and mechanisms for resolving conflict. By the time the YLFS Project began in 2011, CAN had already established a close relationship with the farmers, their communities, and the cooperatives to which the farmers belonged. Ongoing reflection throughout the YLFS Project enabled partners to raise concerns and remain accountable to commitments.

\section{Timeline}

\subsection{Phase 1 (2011-2013)}

The first phase of the YFLS Project focused on the design of a participatory monitoring and evaluation system, implementation of a comprehensive baseline study of food insecurity and household livelihoods in the communities, the consolidation of the project's youth- and women-centered methodology, training of youth leaders, and capacity building in agroecological food production with a strong focus on diversification. Diversification strategies included homegardens, coffee shade of fruit, wood, and fuel trees, patios with root and tuber crops, and protein (chicken and eggs) production. Thus, vegetable-focused homegardens were part of a larger production diversification strategy to improve household dietary diversity and diversify income streams, with women as the primary agents implementing these diversification strategies. The introduction and development of homegardens faced three challenges during phase one, which revealed the need to focus capacity-building on the recuperation of traditional knowledge, combined with collective innovation and adaptation.

In San Ramon, the first challenge was that vegetable-focused homegardens were not common. As one woman explained, they "had not done this since their grandmother's time". It was not a new practice, but knowledge of production techniques, preparation and seed-saving had been impacted by the dominance of coffee-production for export and the influx of processed foods (locally referred to as "comida chatarra"). A team of youth leaders, trained as promoters for the project, led capacity-building focused on basic gardening and food production techniques, including seed selection, germination, transplanting, soil building and improvement technologies, and associative and rotational planting.

As production improved, a second challenge arose. An annual monitoring and evaluation survey revealed that many families were not eating the food they were growing, rather feeding most of the vegetables to their pigs and other small livestock. In a follow-up workshop with the women gardeners 
to analyse and interpret data from the survey, we learned they were unfamiliar with different ways to prepare the wide variety of newly available vegetables. Together, CAN, UCA San Ramon, women gardeners and youth promoters developed a series of nutrition workshops that culminated in a vegetable-focused cookbook. Local women and youth promoters led the nutrition workshops, in which traditional and new recipes were shared and tested with locally available plants. The resulting cookbook, printed and distributed to women gardeners, captured traditional recipes such as guiso de ayote (squash stew) and indio viejo (vegetable, corn, green banana and beef stew) and innovations such as "powerful bean soup" and pancakes made from the leaves of cassava developed through the workshops. Nutrition information was included with each recipe to further promote dietary diversity.

Finally, a third challenge arose in the second year, when women gardeners required another allotment of seeds through the YLFS Project. Women gardeners had not saved seed or rootstock from their garden plants, or had been unable to save seed from certain plants like carrots or onions. In order to ensure the long-term sustainability of gardens, women re-focused garden production on the plants that could produce viable seed under local conditions, especially traditional varieties, and the project provided training to the women and youth in household seed saving techniques for vegetable and fruit seed, and reproductive material.

By the end of the second year, women gardeners felt comfortable and confident in their gardens and were selling vegetables out of their homes. In the years that followed, families developed a vibrant informal seed exchange system within and among communities. When it was found that there was no existing formal market for the vegetables produced in the homegardens, the cooperatives developed regular monthly farmers' markets in the nearby municipal centre of San Ramon. In addition, a group of women established a café where they sell cappuccinos and lattes made from their own coffee and prepared meals created from the excess vegetables and fruits from the homegardens associated with the project. By the fifth year of the YLFS Project, dietary diversity scores had increased from 6.6 to 7.5 , and $85 \%$ of project participants had diversified their income through the sale of fruits, vegetables, eggs and other value-added products made from these materials. In general, a higher level of dietary diversity (higher scores) is an indicator that families are consuming a more diverse diet. In the context of this project, this meant families were increasing the intake of vegetables, fruits and additional proteins to a diet based largely on cereal grains and legumes.

\subsection{Phase 2 (2013-2015)}

The second phase of the YLFS Project built upon the foundations established during Phase 1, and, based on lessons learned, incorporated or deepened the following components:

- Strengthening the focus on women's income generation;

- Youth capacity building and leadership training;

- Nutrition education;

- Water access for consumption and irrigation during the dry season;

- Soil health;

- Access to quality seed; and

- Access to staple foods during months of food scarcity.

The second phase also coincided with the outbreak of La Roya (coffee leaf rust disease-Hemileia vastatrix) in San Ramon. During this difficult period, when farmers experienced a $65 \%$ loss in their coffee harvest, the importance of diversification strategies became clear. Despite the loss of coffee income, reductions in seasonal hunger since the beginning of the project continued. The YLFS project had reduced seasonal hunger from 4.6 to 2.3 months over five years. Women project participants credited the safety net of additional food and income generated through diversification strategies. Over the previous three years, women had been empowered to lead the improvement of the sustainability of their family's livelihoods and they recognized their contribution. However, the outbreak of La Roya made another aspect of diversification clear-the strategies had focused heavily on alternative sources 
of food and income, overlooking the critical need to build soil fertility and resistance to shocks in coffee production.

Due to La Roya, soil health took on greater importance during Phase 2 of the YLFS Project. Farmers participated in farmer-to-farmer exchanges to learn about agroecological production techniques that build soil fertility. However, rather than moving toward adapting these practices to their own coffee production, cooperative members (mostly male) involved in AgroEco ${ }^{\circledR}$ Coffee became increasingly risk averse. As AgroEco ${ }^{\circledR}$ Coffee farmers gathered to collectively decide on how to invest the "Sustainable Agriculture Fund (SAF)", a tense conversation ensued. They had made a commitment to an agroecological transition, but in the context of the coffee leaf rust epidemic, renovating (or re-planting coffee plants killed by la Roya) their coffee fields without agri-chemical inputs was a difficult decision to make. Although the CAN AgroEco ${ }^{\circledR}$ coffee standards requires farmers to invest the funds from the SAF on agroecologically-based practices, CAN decided to have flexibility and allow some farmers to use the funds to respond to the crisis as they saw fit. This generated some tension, but also showed an ability from all partners to compromise and maintain the PAR-based relationship.

At the same time, CAN and the UCA San Ramon wanted to strengthen women's access to capital. Progress had been made with the homegardens and farmers' markets directed primarily at women, but it was evident that women (while not officially members of the cooperative) were contributing more labour to coffee production (and other agricultural and household labour) than they were being compensated for. With all supply chain actors present at the negotiating table, the Women's Unpaid Labour Fund was created (two years after the Sustainable Agriculture Fund) to economically empower women. Women's access to capital shifted the conversation about the risk of an agricultural transition in the face of la Roya. The women's group (cooperative members and spouses of cooperative members) stepped forward and decided to invest their fund in purchasing seeds and materials for coffee nurseries to experiment with agroecological renovation of 0.5 hectares each in their family coffee parcels. In support of the women's efforts to experiment with agroecological renovation, CAN, youth leaders, and the UCA San Ramon's extensionists convinced the whole group of AgroEco ${ }^{\circledR}$ Coffee farmers (i.e., their male counterparts) to invest resources from the "Sustainable Agriculture Fund" towards agroecological practices. This included buying natural inputs (raw flour, molasses, rock minerals, etc.) for making artisanal fertilizers, as well as materials to make foliar sprays for disease suppression, made from culturing fungi in leaf litter collected from the mountains above their communities [45].

At a calculated cost of about one tenth of conventional fungicides and fertilizers, the coffee plantations showed recovery from the disease outbreak, and new plants exhibited resistance. The efficacy of these agroecological soil health and plant nutrition techniques has become evident: the plants were robust and even starting to fruit after only 17 months in the ground. CAN and the UCA San Ramon then facilitated farmer-to-farmer exchanges so that coffee farmers from seven neighbouring cooperatives engaged in the Project could learn the same techniques. The learning exchanges included capacity building in the elaboration of nine different soil and foliar applications, including compost, worm compost, effective microorganisms, biofertilizers, and mineral foliar applications for both food and coffee production areas. Investments were made in barrels and other equipment to allow groups to produce the fertilizers and preparations collectively, where appropriate. Since then, the women's group has expanded agroecological coffee plots to a little over a total of 10 hectares, and men and women gather every other Saturday to collectively make organic fertilizers to support their ongoing agroecological coffee renovation [46].

\subsection{Key Characteristics of the Process}

- Long-term relationships based in solidarity, trust and accountability. CAN's projects begin with a three-year commitment (which have grown into 7+ year partnerships) to accompany partners through the change process with capacity-building in PAR and collectively-identified areas of 
need, horizontal learning exchanges and direct investment in community development. In the case of the YLFS project, CAN built upon earlier relationships established by affiliated researchers, which then led to direct accompaniment for five years, supporting community development to advance in food sovereignty. CAN recognizes that systemic change is a long-term process, and continues its relationship with the UCA San Ramon through AgroEco ${ }^{\circledR}$ Coffee and a revolving fund to support women's economic initiatives.

- Although the AgroEco ${ }^{\circledR}$ coffee model has had success with a small number of farmers in Nicaragua and Mexico, it has been challenging to upscale it. This is because managing higher volumes of coffee would require a significant increase in investment of both human and financial resources towards AgroEco within CAN. The organization is currently assessing the challenges and benefits of pursuing an expansion of AgroEco.

- A focus on increasing the participation of youth, coupled with intergenerational interactions, was a key component and innovation of this project. The importance of young people to continue and improve the livelihoods and landscapes of coffee regions is a theme that has persistently arisen throughout CAN's long history of work in Mesoamerica. The leadership of cooperatives, which tend to be older men, has frequently raised it as an important issue. This project sought to explicitly and directly respond to this issue, and contribute to a better understanding of how young people perceive and engage with some of the challenges these coffee communities are facing.

- Gender equity was incorporated as a transversal strategy across the different components of the YLFS Project. This created an opportunity to ensure broad participation across social groups involved in the project and a recognition of women's reproductive and productive work by both men and women. As the YLFS project worked to increase women's leadership in decision-making and income generation, the intergenerational partnership with youth leaders was crucial in providing support to women-focused initiatives, which could inadvertently create a burden of additional labor on women.

\subsection{Synthesis}

The YLFS Project launched with a focus on diversification strategies as an agroecological pathway to reducing seasonal hunger among coffee-farming families. The multiple challenges faced by the integration of vegetable-focused homegardens in crop production systems demonstrates the critical role of reflection that characterizes PAR processes, along with a willingness to change course. CAN relied on annual surveys (in collaboration with youth promoters) to monitor the progress of diversification strategies. These formed the basis of workshops where survey data was collectively analyzed and interpreted by all stakeholders (CAN, UCA San Ramon, youth promoters, women's groups and cooperative members). As each challenge with homegardens emerged from the survey data, production techniques, food preparation and seed-saving-collective gatherings (workshops, focus groups, and community meetings) were used to reflect on survey results. This created a deeper understanding of the reasons leading to each challenge, and in turn, a collective response that incorporated project participants' perspectives, capacities and aspirations. Each response to the garden challenges was characterized by a willingness by youth promoters to share new capacities, turn to elders to support the recuperation of traditional knowledge, and support farmer experimentation to adapt homegardens to local conditions. It was also critical that CAN and the UCA San Ramon, while in the position to direct funds for the YLFS Project, allowed youth and community members to lead the development of response plans.

Meanwhile, the La Roya epidemic demonstrated the need to maintain flexibility and engage in open-ended processes in the face of external threats beyond the control of community members or the YLFS project. The AgroEco ${ }^{\circledR}$ Coffee farmers' reticence to agroecological renovation reflected a very real concern regarding the best way to protect their families from a complete loss of coffee income. Yet, they had committed to an agroecological transition through their participation in CAN's AgroEco ${ }^{\circledR}$ 
Coffee program. Rather than CAN ending its relationship with the farmers, it pursued delicate and difficult discussions that ultimately allowed for an unexpected pathway to an agroecological transition to emerge. Women farmers-often side-lined in decision-making processes regarding coffee due to their lower level of cooperative membership-used their newly available capital from AgroEco ${ }^{\circledR}$ Coffee's "Women's Unpaid Labor Fund" to propose an alternative. Their willingness to experiment with agroecological renovation created an alternative pathway to the same end-goal, slowly bringing along their male counterparts as the outcome of agroecological renovation becomes apparent.

Finally, the iterative cycles of the PAR process created an opportunity for mutual learning that engaged all stakeholders in the YLFS Project and AgroEco ${ }^{\circledR}$ Coffee. The compounding shock of la Roya epidemic, along with three years of drought, required adaptation and problem-solving around the majority of diversification strategies. The original impetus for the YLFS project, developed through a participatory approach with the UCA San Ramon, was the development of alternative food and income sources for farmers' whose livelihoods had become overly dependent on coffee (whose prices were beyond their control). However, five years of data collection, reflection and experimentation clarified everyone's understanding of the positive mitigating effects of the diversification strategies being promoted, and crystalized the vision of this project towards climate change resiliency. Food security and sovereignty align with this vision by sharing a focus on the empowerment of families and communities to ensure for themselves availability and access to food, at all times of the year, in any year. Furthermore, the lens of climate change resiliency allowed everyone to look at the entire panorama of factors affecting food security - from climate, to political structures, and to the quality of the soil.

\subsection{Lessons Learned}

- Careful systemic investigation of issues (i.e., participatory monitoring and evaluation surveys, reflection workshops), result in more robust solutions, continually refined and adapted to context-specific conditions.

- Adequate investment of time in consistent reflection with all stakeholders is critical to identify what worked and what did not, and why. In addition, power relations and diversity across and within each stakeholder group must be addressed in order to create an inclusive reflection process that builds solutions from multiple perspectives.

- Cross-generational collaboration, in this case teaming up youth promoters and women's' groups, amplified marginalized voices and generated creative alternatives. This was a particularly powerful approach for addressing gender inequality at the household and cooperative level, ultimately exposing alternative pathways towards agroecological transition.

- Identifying 'testers' or farmers willing to engage in experimentation (i.e., vegetable-focused homegardens and agroecological renovation of coffee) can lead to behavior change as other community members have the opportunity to observe positive outcomes (i.e., seeing is believing).

\section{Discussion}

To differing degrees and in different ways, the two previous case studies offer examples of integration between agroecology and PAR. In this section, we discuss these experiences in relation to a growing body of work that examines the integration of agroecology and PAR in different settings and contexts.

Levidow, et al. (2014) propose that a PAR approach to agroecology has great potential to support a transformation towards more sustainable agrifood systems in the European Union. They argue that "To break the lockout of agroecological research and to give it a transformative role, there is need for participatory research combining the science of dynamic complexity with the knowledge of farmers in local contexts" [47]. This aligns with the principles of PAR and agroecology outlined in the case studies, and supports the notion that agrifood system transformations will require a shared interest in undertaking research and co-creating knowledge by farmers and academics. However, the 
authors caution that shifting towards this type of research is rife with challenges and "requires deep institutional reforms, including changes in funding procedures and research organization ... But such efforts run up against institutional limits of agricultural research institutes and state funding bodies, especially their modernist-productivist agendas, reward structures and short-term grants." (p. 1137).

In southern Spain, a long-term PAR process also exemplified the principle of collective action, with researchers, farmers and consumers joining to establish networks for organic food, from farms to schools and households [27]. Through a 5-phase process, emphasizing skill development, the authors reached a stage where farmers and consumers transform from 'beneficiaries' to protagonists, and the role of researchers shifts towards facilitation. One of the key challenges presented in this case is the need for long-term funding, which resonates with all of the experiences that we present in this paper. The multi-actor process that was developed, and which emphasized trusting relationships, building capacities and achieving desired outcomes required a stable and adequate investment of time from the partners involved, and the resources to support them. Similar to the El Salvador case study, maintaining this level of commitment and support became challenging over time, especially for researchers.

Bezner-Kerr and colleagues (2016) exemplify the importance of the commitment to the participation principle in a long-term process linking food sovereignty, agroecology and resilience with farmers in Malawi. Farmer participation through the contribution of knowledge and involvement in experimentation was key for them to identify practices that could support both food sovereignty and resilience. In addition, the reflection and dialogue that occur in PAR allowed for deeper discussions related to gender and economic inequalities. Although these complex issues may not be resolved entirely by PAR in agroecology, it can help to raise awareness about them and start conversations that can lead to seeking solutions [13]. This case compares well to the CAN case study, where gender dynamics played an important role in defining the outcomes of the agroecological interventions.

The principle of humility - whether it is explicit or implicit in a process-seems to be present in most agroecology and PAR initiatives. In El Salvador, the initial humility of the lead researcher, which sought to 'level the playing field' for more equitable negotiations was essential to begin the process. In Nicaragua, a commitment to listening to farmers and paying special attention to groups frequently marginalized (i.e., women and youth) allowed for directing the process towards successful integration of these populations. Another example from Andalusia, Spain, discusses an explicit attempt to break down hegemonic barriers in order to examine the perceptions and challenges of organic standards among small and medium scale farmers. This process was characterized by researchers intentionally showing farmers they were not engaging them from a position of superiority [19]. In terms of standards from the European Union, farmers were accustomed to having little participation, and felt disempowered to seek alternatives that could work better for them. The authors further reinforce their argument by discussing the importance of power dynamics and a characterization of participation in research processes, which can range from manipulative, to one that supports self-mobilization of actors. This example also points to the need for medium and longer term initiatives, which, although challenging to sustain, are essential for PAR and agroecology processes to evolve.

Finally, a long-term PAR and agroecology process in Estelí, Nicaragua presents an admirable model of investing in trust and accountability with smallholder coffee farming cooperatives [28]. In this initiative, researchers from Santa Clara University and the Community Agroecology Network (CAN) led a multi-actor partnership to better understand and propose solutions for seasonal food insecurity periods affecting cooperative members. Several of the researchers had developed long-term relationships with the cooperative leadership, which allowed for a very successful PAR process to address the 'hungry months'. Efforts to maintain trust and transparency included researchers sharing all grant proposal documents (translated to Spanish) with the cooperative leadership, waiting for feedback before moving forward, and maintaining a consistent presence at the site. These actions also required a long-term time investment, which was similar to the El Salvador case study, as well as the Spanish and Malawi examples. An important characteristic of this process is that by successfully 
recruiting the right Nicaraguan partners, including a strong cooperative, this initiative has been able to maintain itself for a long period time.

\section{Conclusions: Future Directions for Integrating Agroecology and PAR}

Some of the key principles identified for effective PAR agroecological processes include a shared interest in research by partners, a belief in collective power/action, a commitment to participation, practicing humility and establishing trust and accountability. Important lessons that we extracted from the PAR and agroecology processes we reviewed include: (1) research processes that did not start as PAR can evolve into a PAR process with intention and commitment; (2) farmer/stakeholder participation in setting the research agenda and design from the onset, results in higher engagement and enhanced research and action outcomes; (3) identifying and recruiting the right partners is critical to achieving desired outcomes; (4) intentional and explicit reflection is an essential component of PAR processes; and (5) PAR processes can serve to identify and integrate marginalized groups, such as women and youth, which is crucial for longer-term and more equitable benefits.

Development organizations and farmer groups alike have also called for a new way of doing research and the need to train the next generation of researchers. PAR is a fitting approach for agroecology, which seeks to contribute to a transformation towards healthier, more sustainable food systems. In addition, while just as 'action' is a core component of Participatory Action, and movement is core to agroecology, each of these are potential areas of discomfort for many scientists who are still trying to maintain 'objectivity', or survive within the limits of the time and funding parameters of academia. Working within the frame of PAR and maximizing the contributions of all actors may require that other partners address the movement and action—but it is essential that they remain part of the research process. Strong collaborations that represent multiple organizational types is the best interim solution, since purely academic endeavors of agroecology and PAR will fail to achieve real change if disconnected from political processes and/or social movements.

Acknowledgments: The authors wish to thank their partner coffee farming communities from Central America and Mexico for their willingness to participate, learn and challenge in the PAR processes presented in this paper. Funding for case study work was provided by a diversity of donors, but the time invested for this paper was not part of this funding.

Author Contributions: V. Ernesto Méndez conceived the original idea for the paper, led the process, conducted final revisions and was responsible for submission. All authors contributed to further developing the ideas presented, the structure, and content, as well as the writing and editing of the paper.

Conflicts of Interest: The authors declare no conflicts of interest.

\section{References}

1. Méndez, V.E.; Bacon, C.M.; Cohen, R. Introduction: Agroecology as a transdisciplinary, participatory and action-oriented approach. In Agroecology: A Transdisciplinary, Participatory and Action-Oriented Approach; Méndez, V.E., Bacon, C.M., Cohen, R., Gliessman, S.R., Eds.; CRC Press/Taylor and Francis: Boca Raton, FL, USA, 2016; pp. 1-22.

2. Gliessman, S.R. Agroecology: The Ecology of Sustainable Food Systems, 3rd ed.; CRC Press/Taylor \& Francis: Boca Raton, FL, USA, 2015.

3. Méndez, V.E.; Bacon, C.M.; Cohen, R.; Gliessman, S.R. Agroecology: A Transdisciplinary, Participatory and Action-Oriented Approach; CRC Press/Taylor and Francis: Boca Raton, FL, USA, 2016.

4. Francis, C.A.; Lieblein, G.; Breland, T.A.; Salomonsson, L.; Geber, U.; Sriskandarajah, N.; Langer, V. Transdisciplinary research for a sustainable agriculture and food sector. Agron. J. 2008, 100, 771-776. [CrossRef]

5. Ruiz-Rosado, O. Agroecology: A discipline leading towards transdiscipline. Interciencia 2006, 31, 140-145.

6. Wezel, A.; Bellon, S.; Dore, T.; Francis, C.; Vallod, D.; David, C. Agroecology as a science, a movement and a practice. A review. Agroecol. Sustain. Dev. 2009, 29, 503-515. [CrossRef]

7. Kindon, S.; Pain, R.; Kesby, M. Participatory Action Research Approaches and Methods; Routledge: Oxon, UK, 2007.

8. Whitmer, A.; Ogden, L.; Lawton, J.; Sturner, P.; Groffman, P.M.; Schneider, L.; Hart, D.; Halpern, B.; Schlesinger, W.; Raciti, S.; et al. The engaged university: Providing a platform for research that transforms society. Front. Ecol. Environ. 2010, 8, 314-321. [CrossRef] 
9. James, E.A.; Milenkiewicz, M.; Bucknam, A. Participatory Action Research for Educational Leadership: Using Data-Driven Decision Making to Improve Schools; Sage Publications: New York, NY, USA, 2008.

10. Minkler, M.; Wallerstein, N. Community-Based Participatory Research for Health: From Process to Outcomes, 2nd ed.; Jossey Bass: San Francisco, CA, USA, 2008.

11. Greenwood, D.J.; Levin, M. Introduction to Action Research: Social Research for Social Change; Sage Publications: Thousand Oaks, CA, USA, 1998.

12. Méndez, V.E.; Bacon, C.M.; Cohen, R. Agroecology as a transdisciplinary, participatory, and action-oriented approach. Agroecol. Sustain. Food Syst. 2013, 37, 3-18.

13. Bezner Kerr, R.; Nyantakyi-Frimpong, H.; Lupafya, E.; Dakishoni, L. Food sovereignty, agroecology and resilience: Competing or complementary frames? In An International Colloquium on Global Governance/Politics, Climate Justice $\mathcal{E}$ Agrarian/Social Justice: Linkages and Challenges; Colloquium Paper \# 65; International Institute of Social Studies (IISS): The Hague, The Netherlands, 2016.

14. Fals-Borda, O.; Rahman, M.A. Action and Knowledge: Breaking the Monopoly with Participatory Action-Research; The Apex Press: New York, NY, USA, 1991.

15. Greenwood, D.J.; Whyte, W.F.; Harkavy, I. Participatory action research as a process and as a goal. Hum. Relat. 1993, 46, 175-192. [CrossRef]

16. Jones, L.; Bjelland, D. International experiential learning in agriculture. In Proceedings of the Annual Conference of the Association for International Agricultural and Extension Education, Association for International Agricultural and Extension Education, Dublin, Ireland, 23-29 May 2004; pp. 963-964.

17. Wingenbach, G.J.; Chmielewski, N.; Smith, J.; Piña, M., Jr.; Hamilton, W.T. Barriers to international experiential participation. J. Int. Agric. Ext. Educ. 2006, 13, 79-89. [CrossRef]

18. Bacon, C.; Méndez, V.E.; Brown, M. Participatory Action-Research and Support for Community Development and Conservation: Examples from Shade Coffee Landscapes of El Salvador and Nicaragua; Center for Agroecology and Sustainable Food Systems (CASFS), University of California: Santa Cruz, CA, USA, 2005.

19. Cuéllar-Padilla, M.; Calle-Collado, Á. Can we find solutions with people? Participatory action research with small organic producers in andalusia. J. Rural. Stud. 2011, 27, 372-383. [CrossRef]

20. Bentley, J.W. Facts, fantasies, and failures of farmer participatory research. Agric. Hum. Values 1994, 11, 140-150. [CrossRef]

21. Selener, D. Participatory Action Research and Social Change; Cornell University Press: Ithaca, NY, USA, 1997.

22. Dlott, J.W.; Altieri, M.A.; Masumoto, M. Exploring the theory and practice of participatory research in us sustainable agriculture: A case study in insect pest management. Agric. Hum. Values 1994, 11, 126-139. [CrossRef]

23. Eksvärd, K.; Rydberg, T. Integrating participatory learning and action research and systems ecology: A potential for sustainable agriculture transitions. Syst. Pract. Action Res. 2010, 23, 467-486. [CrossRef]

24. Grudens-Schuck, N. Conflict and engagement: An empirical study of a farmer-extension partnership in a sustainable agriculture program. J. Agric. Environ. Ethics 2000, 13, 79-100. [CrossRef]

25. Cahill, C. The personal is political: Developing new subjectivities through participatory action research. Gend. Place Cult. 2007, 14, 267-292. [CrossRef]

26. Fox, J.A. Lessons from action research partnerships. Dev. Pract. 2006, 16, 27-38. [CrossRef]

27. Guzman, G.I.; Lopez, D.; Roman, L.; Alonso, A.M. Participatory action research in agroecology: Building local organic food networks in spain. Agroecol. Sustain. Food Syst. 2013, 37, 127-146. [CrossRef]

28. Bacon, C.; Sundstrom, W.A.; Flores-Gomez, M.A.; Méndez, V.E.; Santos, R.; Goldoftas, B.; Dougherty, I. Explaining the 'hungry farmer paradox': Smallholders and fair trade cooperatives navigate seasonality and change in nicaragua's corn and coffee markets. Glob. Environ. Chang. 2014, 25, 133-149. [CrossRef]

29. Putnam, H.; Godek, W.; Kissmann, S.; Pierre, J.L.; Alvarado Dzul, S.H.; Calix de Dios, H.; Gliessman, S.R. Coupling agroecology and par to identify appropriate food security and sovereignty strategies in indigenous communities. Agroecol. Sustain. Food Syst. 2013, 38, 165-198. [CrossRef]

30. Putnam, H.; Cohen, R.; Jaffe, R.M. Agroecology as a food security and food sovereignty strategy in coffee-growing communities: Opportunities and challenges in san ramon, nicaragua. In Agroecology: A Transdisciplinary, Participatory and Action-Oriented Approach; Méndez, V.E., Bacon, C.M., Cohen, R., Gliessman, S.R., Eds.; CRC Press/Taylor and Francis: Bocan Raton, FL, USA, 2016; pp. 193-216. 
31. Nyantakyi-Frimpong, H.; Hickey, C.; Lupafya, E.; Dakishoni, L.; Bezner Kerr, R.; Luginaah, I.; Katundu, M. A farmer-to-farmer agroecological approach to addressing food security in northern and central malawi. In Harnessing People's Knowledge for Food System Transformation; Wakeford, T., Sanchez-Rodriguez, J., Chang, M., Buchanan, C., Anderson, C., Eds.; CAWR: Coventry, UK, 2017.

32. Nyantakyi-Frimpong, H.; Mambulu, F.N.; Bezner Kerr, R.; Luginaah, I.; Lupafya, E. Agroecology and sustainable food systems: Participatory research to improve food security among hiv-affected households in northern malawi. Soc. Sci. Med. 2016, 164, 89-99. [CrossRef] [PubMed]

33. Méndez, V.E. Traditional Shade, Rural Livelihoods, and Conservation in Small Coffee Farms and Cooperatives of Western El Salvador. Ph.D. Thesis, University of California, Santa Cruz, CA, USA, 2004.

34. Méndez, V.E.; Gliessman, S.R.; Gilbert, G.S. Tree biodiversity in farmer cooperatives of a shade coffee landscape in western el salvador. Agric. Ecosyst. Environ. 2007, 119, 145-159. [CrossRef]

35. Méndez, V.E. Farmers' livelihoods and biodiversity conservation in a coffee landscape of el salvador. In Confronting the Coffee Crisis: Fair Trade, Sustainable Livelihoods and Ecosystems in Mexico and Central America; Bacon, C., Méndez, V.E., Gliessman, S.R., Goodman, D., Fox, J.A., Eds.; The MIT Press: Cambridge, MA, USA, 2008; pp. 207-236.

36. Méndez, V.E.; Bacon, C.M.; Olson, M.; Morris, K.S.; Shattuck, A.K. Agrobiodiversity and shade coffee smallholder livelihoods: A review and synthesis of ten years of research in central america. Prof. Geogr. 2010, 62, 357-376. [CrossRef]

37. Morris, K.S.; Méndez, V.E.; Olson, M.B. 'Los meses flacos': Seasonal food insecurity in a salvadoran organic coffee farming cooperative. J. Peasant. Stud. 2013, 40, 457-480. [CrossRef]

38. Olson, M.B.; Morris, K.S.; Méndez, V.E. Cultivation of maize landraces by small-scale shade coffee farmers in western el salvador. Agric. Syst. 2012, 111, 63-74. [CrossRef]

39. Bacon, C.M.; Méndez, V.E.; Gliessman, S.R.; Goodman, D.; Fox, J.A. Confronting the Coffee Crisis: Fair Trade, Sustainable Livelihoods and Ecosystems in Mexico and Central America; MIT Press: Cambridge, MA, USA, 2008.

40. Morris, K.S.; Méndez, V.E.; Lovell, S.T.; Olson, M. Conventional food plot management in an organic coffee cooperative: Explaining the paradox. Agroecol. Sustain. Food Syst. 2013, 37, 762-787. [CrossRef]

41. Jaffe, R.; Bacon, C.M. From differentiated coffee markets towards alternative trade and knowledge networks. In Confronting the Coffee Crisis: Fair Trade, Sustainable Livelihoods and Ecosystems in Mexico and Central America; Bacon, C., Méndez, V.E., Gliessman, S.R., Goodman, D., Fox, J.A., Eds.; MIT Press: Cambridge, MA, USA, 2008; pp. 311-336.

42. Tervalon, M.; Murray-Garcia, J. Cultural humility versus cultural competence: A critical distinction in defining physician training outcomes in multicultural education. J. Health Care Poor Underserved 1998, 9, 117-125. [CrossRef] [PubMed]

43. La Via Campesina. International Forum on Agroecology Declaration Brings Common Understanding of Agroecology. 2015. Available online: https://viacampesina.org/en/index.php/main-issues-mainmenu27/ sustainable-peasants-agriculture-mainmenu-42/1765-new-peoples-declaration-brings-commonunderstanding-of-agroecology (accessed on 7 January 2017).

44. Araujo, S. Farmworkers Lead the Way on People's Agroecology in the U.S. 2015. Available online: https: / / whyhunger.org/connect/item/2770-farmworkers-lead-the-way-on-peoples-agroecology-in-the-u-s (accessed on 7 January 2017).

45. Putnam, H. Women Taking Risks: Coffee Leaf Rust Crisis in Nicaragua. W-E Digest. February 2016. Available online: http:/ / www.w-edigest.org/dirt-women-taking-risks-experimentation-with-solutions-to-the-coffeeleaf-rust-crisis-in-nicaragua/ (accessed on 20 April 2017).

46. Putnam, H.; Gliessman, S.R. Nicaragua: Beneficial forest microorganisms in coffee production. In Replacing Chemicals with Biology: Phasting Out Highly Hazardous Pesticides with Agroecology; Watts, M., Williamson, S., Eds.; Pestucide Action Network Asia and the Pacific: Pulau Pinang, Malaysia, 2015; pp. 142-144.

47. Levidow, L.; Pimbert, M.; Vanloqueren, G. Agroecological research: Conforming-or transforming the dominant agro-food regime? Agroecol. Sustain. Food Syst. 2014, 38, 1127-1155. [CrossRef]

(C) 2017 by the authors. Licensee MDPI, Basel, Switzerland. This article is an open access article distributed under the terms and conditions of the Creative Commons Attribution (CC BY) license (http:/ / creativecommons.org/licenses/by/4.0/). 